\title{
Fuzzy Comprehensive Evaluation on the Effect of Measures Operation for Oil-Water Well
}

\author{
Zhi-Bin Liu, ${ }^{1,2}$ Wei Qing, ${ }^{1,3}$ and Xin-Hai Kong ${ }^{1}$ \\ ${ }^{1}$ Department of Graduate, Southwest Petroleum University, Sichuan, Chengdu 610500, China \\ ${ }^{2}$ State Key Laboratory of Oil and Gas Reservoir Geology and Exploitation, Southwest Petroleum University, Sichuan, \\ Chengdu 610500, China \\ ${ }^{3}$ Pipe and tooling center, Sinopec Southwest Petroleum Bureau, Sichuan, Deyang 618000, China \\ Correspondence should be addressed to Xin-Hai Kong, kongxinhai2@163.com
}

Received 23 June 2011; Accepted 24 September 2011

Academic Editor: Rustom M. Mamlook

Copyright ( $) 2011$ Zhi-Bin Liu et al. This is an open access article distributed under the Creative Commons Attribution License, which permits unrestricted use, distribution, and reproduction in any medium, provided the original work is properly cited.

The measures operation is an important component of borehole operation, and the operation effects directly affect the increase of oil and gas production. In perspective of the present reality of borehole operation company, the authors analyze the commonly used type of measures on the oil field, summarize six indicators to evaluate the measures operation effect, and give the quantitative calculation method for six evaluation indicators. Through the experts grading method, we can obtain all the weights of indicators and then establish the fuzzy comprehensive evaluation model of operation effect of measures. The evaluation model can be used to evaluate the operation effect of single well, oil block, or the branch company. Based on the actual data of measures operation of a branch company, using the fuzzy comprehensive evaluation approach to evaluate each block in the branch company, this paper obtained the same conclusion as the qualitative analysis.

\section{Introduction}

Petroleum and natural gas are two kinds of important resources in people's material lives and the development process of human civilization. The oil and gas resources in the underground are exploited by way of drilling. But, in the long-term production process, oil-water wells suffer damage from the flow of oil and gas without a break and also from the workover operation in order to maintain normal production and the alteration measures of oil layer in order to enhance oil recovery, which make oil wells change every moment and gradually age, and various types of faults occur, eventually resulting in the fact that the production of oil wells cannot be normal, or is even stop production. Therefore, we must take the borehole operation for the oil-water wells with problems and faults to make the oil wells resume normal production. This means that the borehole operation is an important technology in ensuring the normal production of oil-water wells in the process of oil field development. Moreover, the measures operation is a deciding factor in increasing the production of oil and gas. Currently, the verbal description is the main method to evaluate operation effects in the borehole operation; this only stays on the level of qualitative analysis, and different borehole operation companies for the emphasis on the operation effects are not the same. The most concern for the oil-field companies is the output of oil and gas, and the factors affecting the output of oil and gas are largely determined by the measures of increasing production and injection. Accordingly, this paper analyzes these measures commonly used in oil fields and sums up the evaluation indicators for evaluating the measure effects. According to the daily data record about the measure operation in a borehole operation company, the fuzzy comprehensive evaluation method can be used to evaluate the operation effects of measures. Assume that $U=\left\{u_{1}, u_{2}, \ldots, u_{m}\right\}$ is the set of indicators and $V=\left\{v_{1}, v_{2}, \ldots, v_{n}\right\}$ is the ranking set, the fuzzy compressive evaluation model is defined as $B=W \circ R$, where "०" is an operator notation. Generally, “o" takes $(\wedge, \vee),(\vee, \wedge)$, or $(+, \cdot) . W$ is the weight vector of indicators, and $R=\left(r_{i j}\right)_{m \times n}$ is the evaluation matrix, where $r_{i j}$ is the degree of possibility of the $i$ th indicator belonging to the $j$ th ranking. 


\section{Evaluation Indicators and Their Calculation Method}

In the process of oil-field development, we often meet with some low-permeability reservoirs; even under a larger differential pressure, it is also difficult to obtain high output. And some reservoirs in the drilling process are invaded by drilling fluid, so it will lower the reservoir permeability near the bottom of well, and then lead to decline the oil output. In addition, oil-water wells in the process of production, due to various reasons, will also be blocked near the bottom, making the injected volume for water injection wells and the oil output for oil wells, thus affecting the mining speed and the recovery rate. In these cases, we must implement all kinds of measures to improve these problem reservoirs or wells on oil-field.

On the oil field, the commonly used stimulation measures mainly include hydraulic fracturing, acidizing, sand prevention, water plugging, secondary solidification, sealing channeling [1-4]. Hydraulic fracturing is an important technical measure in increasing the production of oil wells and the injected volume of water wells. It has become a widely used international method. It squeezes a kind of liquid with certain viscosity into the reservoirs through the high pressure, resulting in the reservoirs crack, so as to improve the permeability of reservoirs. And acidizing is a kind of widely used measures in improving the oil reservoir and enhancing the permeability, which utilizes the characteristics that the acid liquor can dissolve salt contained in rock formation to improve the reservoir permeability near wellbore area, so as to achieve the purpose of increasing the oil output and the water injected volume. Sanding is one of the common problems for sandstone reservoir in the recovery process, with great harm, would result in the reservoirs buried by sand or the wellholes plugged by sand, causing oil wells to stop production. The quality of these operating measures is directly related to the benefit of the oil field, therefore it is very urgent to conduct the effect evaluation for these operating measures.

From the point of view of evaluation, we can evaluate from single well a block or the whole oil company and also from single measures or multiple measures. If we evaluate the single measures of an oil well, the workload is very large, because thousands of wells need to be repaired every year for a borehole operation company, and a well may need to use more than one kind of measures simultaneously. Therefore, this paper conducts the effect evaluation in units of blocks. Assume there are $n$ blocks, denoted as $B=\left\{B_{1}, B_{2}, \ldots, B_{n}\right\}$. Through the analysis, we can evaluate the operating effect of measures from the following several aspects.

(1) Incremental Output of Oil $\left(u_{1}\right)$. The incremental output of oil is divided into the net incremental oil output $\left(u_{11}\right)$ and the controlled decreasing oil output $\left(u_{12}\right)$. The net incremental oil output is defined as $u_{11}=Q_{1}-\bar{q} \cdot u_{2}$, where $Q_{1}$ is the cumulative oil production after measures operation, $\bar{q}$ is the average product before measures operation, and $u_{2}$ is the period of validity of an oil-water well. The controlled decreasing oil output is defined as $u_{12}=\bar{q} \cdot u_{2}-Q_{2}$, where $Q_{2}$ is the cumulative oil production calculated by the natural decreasing law based on the output before measures operation. Unit: "ton". As any two blocks are different, this paper compares the relative incremental oil output.

(2) Period of Validity $\left(u_{2}\right)$. The period of validity is defined as $u_{2}=F_{2}-F_{1}$, where $F_{1}$ is the date that the average product after measure operation reaches the ninety percent of the average product before measure operation and $F_{2}$ is the date when the daily production is under the natural decline oil production after measure operation. Unit: “day". Here, compare the average period of validity for each block.

(3) Effective Rate $\left(u_{3}\right)$. The effective rate of measures is defined as $u_{3}=N_{\text {eff }} / N$, where $N_{\text {eff }}$ is the number of effective measures and $N$ is the total of measures. When the average output after the measures can be restored to the previous average output of $90 \%$, we call the measures effective.

(4) Construction Period $\left(u_{4}\right)$. The construction period is defined as $u_{4}=t_{2}-t_{1}$, where $t_{1}$ is the starting date of measures and $t_{2}$ is the data of well completion. Here, compare the average construction period. Unit: "day".

(5) Incremental Volume of Water Injection $\left(u_{5}\right)$. The incremental volume of water injection is defined as $u_{5}=P-\bar{p} \cdot u_{2}$, where $P$ is the cumulative volume of water injection after acidification and $\bar{p}$ is the average volume of water injection before acidification. Unit: “ton”. Because any two blocks are different, this paper compares the relative incremental volume of water injection.

(6) Water Injection Pressure $\left(u_{6}\right)$. Considering the actual situation of different blocks, this paper adopts the percentage of reduced value of water injection pressure to compare each block. The reduced value of water injection pressure is defined as $\Delta f=f_{1}-f_{2}$, where $f_{1}$ is the pressure before acidification and $f_{2}$ is the pressure after acidification, so $u_{6}=$ $\left(f_{1}-f_{2}\right) / f_{1}=\Delta f / f_{1}$.

\section{Weights of Evaluation Indicators}

The importance of different indicators is different in the scheme evaluation, and the measures we describe the size of the importance for an indicator are called the weight of the indicator. The indicator weight is one kind of comprehensive measure including both subjective evaluation and objective expression, reflecting the relative importance between indicators. At present, there have been dozens of methods to determine the weights of indicators [5-8]. This paper proposes a kind of new method to determine the weights of indicators in the following.

(A) $m$ Experts Draw Their Fuzzy Complementary Matrix by Pairwise Comparison Method. Assume that the ith expert compares the above six indicators to get the fuzzy complementary matrix denoted as $R_{i}=\left(r_{s t}\right)_{6 \times 6}(i=1,2, \ldots, m)$. Here, we take the quantity scale of $0.1 \sim 0.9$ (see Table 1 ). 
TABLE 1: The quantity scale of $0.1 \sim 0.9$.

\begin{tabular}{|c|c|c|}
\hline Scale value & Definition & Explanation \\
\hline 0.5 & Equally important & Two elements compared, equally important. \\
\hline 0.6 & Slightly important & $\begin{array}{l}\text { Two elements compared, an element is more slightly important } \\
\text { than another element. }\end{array}$ \\
\hline 0.7 & Obviously important & $\begin{array}{l}\text { Two elements compared, an element is more obviously important } \\
\text { than another element. }\end{array}$ \\
\hline 0.8 & Much more important & $\begin{array}{l}\text { Two elements compared, an element is much more important than } \\
\text { another element. }\end{array}$ \\
\hline 0.9 & Extremely important & $\begin{array}{l}\text { Two elements compared, an element is more extremely important } \\
\text { than another element. }\end{array}$ \\
\hline $0.1,0.2,0.3,0.4$ & Converse comparison & $\begin{array}{l}\text { If } u_{i} \text { is compared with } u_{j} \text {, get the judgment value } r_{i j} \text {, then } u_{j} \text { is } \\
\text { compared with } u_{i} \text {, the judgment value is } r_{j i}=1-r_{i j} \text {. }\end{array}$ \\
\hline
\end{tabular}

TABLE 2: The grading values of $m$ experts.

\begin{tabular}{ccccccc}
\hline & Indicator $u_{1}$ & Indicator $u_{2}$ & Indicator $u_{3}$ & Indicator $u_{4}$ & Indicator $u_{5}$ & \multicolumn{2}{c}{ Indicator $u_{6}$} \\
\hline Expert 1 & $C_{11}$ & $C_{12}$ & $C_{13}$ & $C_{14}$ & $C_{15}$ & $C_{16}$ \\
Expert 2 & $C_{21}$ & $C_{22}$ & $C_{23}$ & $C_{24}$ & $C_{25}$ & $C_{26}$ \\
$\vdots$ & $\vdots$ & $\vdots$ & $\vdots$ & $\vdots$ & $\vdots$ & $\vdots$ \\
Expert $m$ & $C_{m 1}$ & $C_{m 2}$ & $C_{m 3}$ & $C_{m 4}$ & $C_{m 5}$ & $C_{m 6}$ \\
\hline
\end{tabular}

(B) Summarize the Experts Grading Values. Assume that the grading value of the $i$ th expert aiming at the indicator of $u_{j}$ is denoted by $C_{i j}=\sum_{t=1}^{6} r_{j t}$, then the grading values of $m$ experts are shown in Table 2.

(C) Calculate the Weights of Indicators. The weights can be obtained by means of the following expression:

$$
w_{j}=\frac{\sum_{i=1}^{m} C_{i j}}{\sum_{j=1}^{6}\left(\sum_{i=1}^{m} C_{i j}\right)},
$$

where $w_{j}$ is the weight of $j$ th indicator, $C_{i j}$ is the scoring value of $i$ th expert to the $j$ th indicator, and $m$ is the number of experts.

\section{Fuzzy Comprehensive Evaluation on the Measure Operation Effect}

The fuzzy comprehensive evaluation method is a kind of evaluation method with combining fuzzy theory and mathematical model. According to the given evaluation criteria and the measured values, by means of the fuzzy transformation, we can make evaluation of things. The specific evaluation steps are as follows.

(a) Determine the indicator set of operation evaluation of measures $U=\left\{u_{1}, u_{2}, u_{3}, u_{4}, u_{5}, u_{6}\right\}$. Here, $u_{1}$ : incremental output of oil and gas; $u_{2}$ : period of validity; $u_{3}$ : Effective rate; $u_{4}$ : construction period; $u_{5}$ : incremental volume of water injection; $u_{6}$ : water injection pressure.

(b) Determine the ranking set of operation effect $V=$ $\left\{v_{1}, v_{2}, v_{3}, v_{4}, v_{5}\right\}$. Here, take $V=$ better, good, general, bad, and worse $\}$. (c) Determine the weights of all the evaluation indicators $W$. We can get the weights by (1).

(d) Write out the evaluation matrix $R=\left(R_{1}, R_{2}, R_{3}, R_{4}\right.$, $\left.R_{5}, R_{6}\right)^{T}, R_{i}=\left(r_{i 1}, r_{i 2}, r_{i 3}, r_{i 4}, r_{i 5}\right)$, where $r_{i j}$ is the degree of possibility of the $i$ th indicator belonging to the $j$ th ranking.

(e) Establish the fuzzy evaluation model: $B=W \circ R$, where "०" is an operator notation, here taking $(+, \cdot)$.

(f) Calculate the evaluation values of indicators $B$ and normalizing. According to the maximum subordinate principle, we can obtain the fuzzy comprehensive evaluation results.

The above evaluation matrix $R$ is determined based on a specific block, for different blocks; its value is different. In order to have a clear sequencing for the measure effects of all the blocks on an oil-field, it can conduct the following processing.

Assume that there are $n$ blocks needing to be evaluated, with 6 indicators of evaluation, so the attribute matrix of all the indicators can be defined as $Y=\left(y_{i j}\right)_{n \times 6}$. Since the attributes are generally incommensurate, the attribute matrix needs to be normalized so as to transform the various attribute values into comparable values. For the convenience of calculation and extension, the following two functions are used to calculate the degree of membership.

When the $j$ th indicator is the benefit type, the function is defined by

$$
\begin{gathered}
x_{i j}=\frac{y_{i j}-\min _{1 \leq i \leq n}\left\{y_{i j}\right\}}{\max _{1 \leq i \leq n}\left\{y_{i j}\right\}-\min _{1 \leq i \leq n}\left\{y_{i j}\right\}}, \\
i=1,2, \ldots, n, \quad j=1,2, \ldots, 6 .
\end{gathered}
$$


When the $j$ th indicator is the cost type, the function is defined by

$$
\begin{gathered}
x_{i j}=\frac{\max _{1 \leq i \leq n}\left\{y_{i j}\right\}-y_{i j}}{\max _{1 \leq i \leq n}\left\{y_{i j}\right\}-\min _{1 \leq i \leq n}\left\{y_{i j}\right\}}, \\
i=1,2, \ldots, n, \quad j=1,2, \ldots, 6 .
\end{gathered}
$$

In the above-mentioned six indicators, the incremental output of oil and gas, the period of validity, the effective rate, and the incremental volume of water injection are the benefit type, while the construction period and the water injection pressure are the cost type. By (2) and (3), the data matrix $Y=\left(y_{i j}\right)_{n \times 6}$ can be transformed into a decision matrix, denoted as $X=\left(x_{i j}\right)_{n \times 6}$, and $x_{i j} \in[0,1](i=1,2, \ldots, n, j=$ $1,2, \ldots, 6)$.

According to the grading values given by experts, through (1), we can get the weight vector of all the six indicators $W=\left(w_{1}, w_{1}, \ldots, w_{6}\right)^{T}$. By $B=W \cdot X^{T}$, we finally obtain the comprehensive effects for all the blocks $B=\left(B_{1}, B_{2}, \ldots, B_{n}\right)^{T}$.

\section{Application}

The operation data of measures of a borehole operation company in 2010 is as follows.

Crude oil production is 4.78 million tons, 275600 tons of which is the incremental production of measures. All measures are 696 times, and the effective measures are 561 times. The period of validity of measures is 289 days, and the average construction period for measures is 7 days. In 2010, the total volume of water injection is 39.41 million cubic meters, compared with 2009, more than 2.56 million cubic meters. The average injection pressure of 2010 is $24 \mathrm{MPa}$, and in 2009 the average water pressure is $31 \mathrm{MPa}$.

Through the experts grade, the weight vector of indicators is decided by

$$
W=\left\{\frac{0.31}{w_{1}}, \frac{0.14}{w_{2}}, \frac{0.22}{w_{3}}, \frac{0.08}{w_{4}}, \frac{0.13}{w_{5}}, \frac{0.12}{w_{6}}\right\}
$$

From the above data, we can obtain the following.

(i) Relative incremental oil production of measures: $u_{1}=27.56 / 478=5.77 \%$.

(ii) Period of validity: $u_{2}=289$.

(iii) Effective rate: $u_{3}=561 / 696=80.6 \%$.

(iv) Average construction period: $u_{4}=7$.

(v) Relative incremental volume of water injection: $u_{5}=$ $256 / 3941=6.50 \%$.

(vi) Relative drop pressure of water injection: $u_{6}=(31-$ $24) / 31=22.58 \%$.
Through the random survey for these on-site oil workers, we acquire the following evaluation matrix:

$$
R=\left(\begin{array}{lllll}
0.15 & 0.27 & 0.38 & 0.14 & 0.06 \\
0.13 & 0.34 & 0.25 & 0.17 & 0.11 \\
0.37 & 0.31 & 0.26 & 0.13 & 0.03 \\
0.21 & 0.26 & 0.35 & 0.12 & 0.06 \\
0.11 & 0.24 & 0.33 & 0.25 & 0.08 \\
0.28 & 0.23 & 0.21 & 0.16 & 0.12
\end{array}\right) .
$$

The comprehensive evaluation value can be obtained:

$$
B=W \circ R=\left\{\frac{0.2108}{v_{1}}, \frac{0.2791}{v_{2}}, \frac{0.3061}{v_{3}}, \frac{0.1571}{v_{4}}, \frac{0.0702}{v_{5}}\right\} .
$$

Therefore, the operation effect of this company in 2010 is "general."

\section{Conclusions}

In this paper, we establish the fuzzy comprehensive evaluation model to evaluate the effect of measures operation for the oil-water well. It is favorable to solve the evaluation problem about the operation effect of measures and also provide a reference for the downhole operation company in decision making. First of all, we analyze the effect factors of measures operation in the process of oil-field development and put forward six indicators to evaluate the operation effect of measures. Secondly, we present a kind of new method to determine the weights of evaluation indicators. Then, summarize the steps to evaluate the operation effect of measures. Finally, based on the actual data of measures operation of a branch company, using the fuzzy comprehensive evaluation method to evaluate the operation effect of measures, this paper obtains the same conclusion as the qualitative analysis.

\section{Acknowledgments}

Thanks are due to the support by National Natural Science Foundation of China (no. 50874094).

\section{References}

[1] S. Q. Sun, Borehole Operation, Petroleum Industry Press, Beijing, China, 2006.

[2] J. L. Wang and T. J. Zhang, Borehole Operation, Petroleum Industry Press, Beijing, China, 2006.

[3] Y. C. Li, Oil Extraction Engineering, Petroleum Industry Press, Beijing, China, 2009.

[4] J. X. Wang, Technology of Increasing Production and Augmented Injection of Oil-Water Well, China University of Petroleum Press, Beijing, China, 2009.

[5] Z. P. Fan, J. Ma, and Q. Zhang, "An approach to multiple attribute decision making based on fuzzy preference information on alternatives," Fuzzy Sets and Systems, vol. 131, no. 1, pp. 101-106, 2002. 
[6] Y. J. Lu, "Weight calculation method of fuzzy analytical hierarchy process," Fuzzy Systems and Mathematics, vol. 16, no. 2, pp. 79-85, 2002.

[7] J. J. Zhang, "A new ranking method of fuzzy complementary judgment matrix," Operations Research and Management Science, vol. 14, no. 2, pp. 59-63, 2005.

[8] Y. J. Lu, W. L. Shi, and X. R. Guo, "The conditions of rank preservation and a general Priority formula for fuzzy complementary judgment matrix," Mathematics in Practice and Theory, vol. 39, no. 15, pp. 153-158, 2009. 

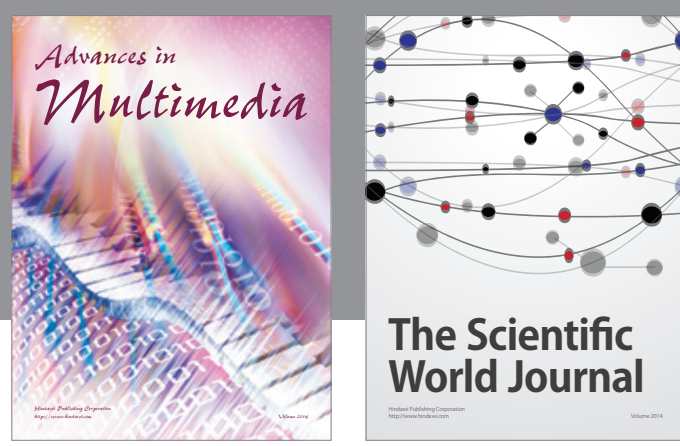

The Scientific World Journal
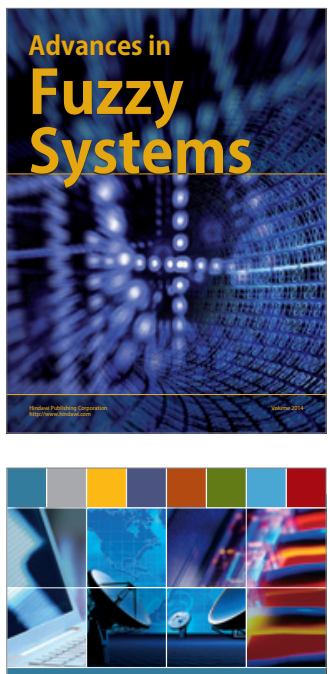

Computer Networks and Communications
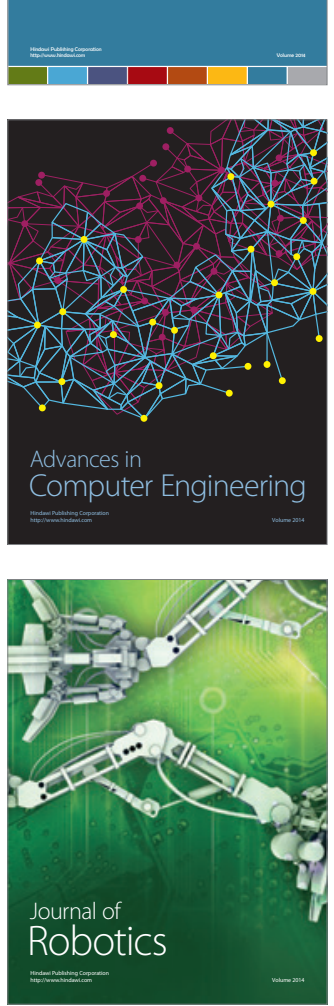
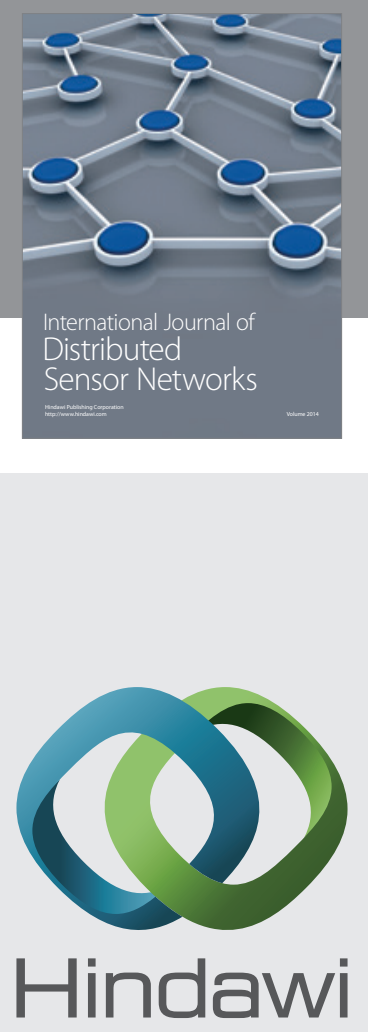

Submit your manuscripts at

http://www.hindawi.com
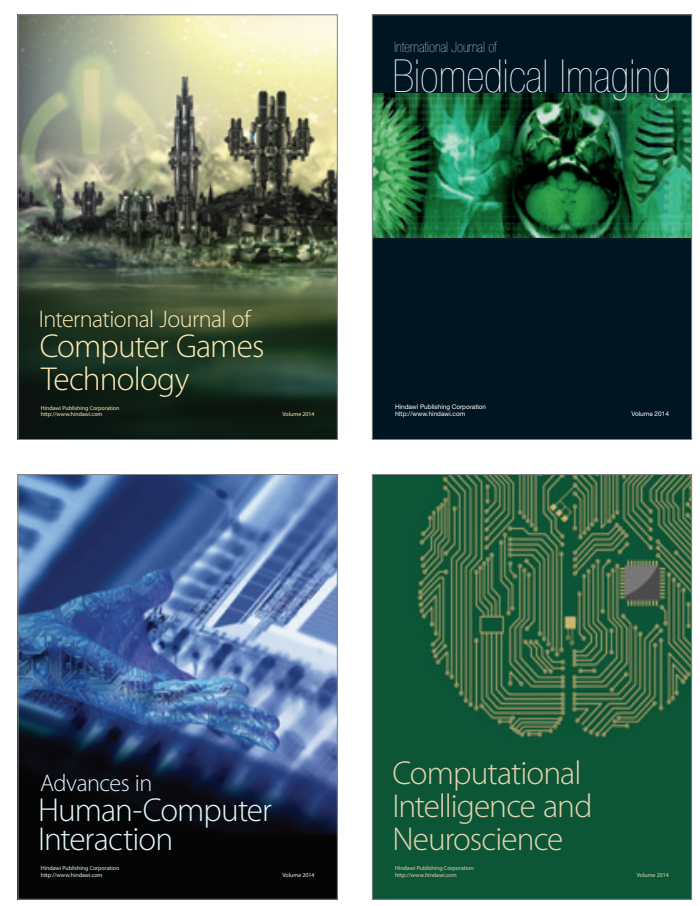
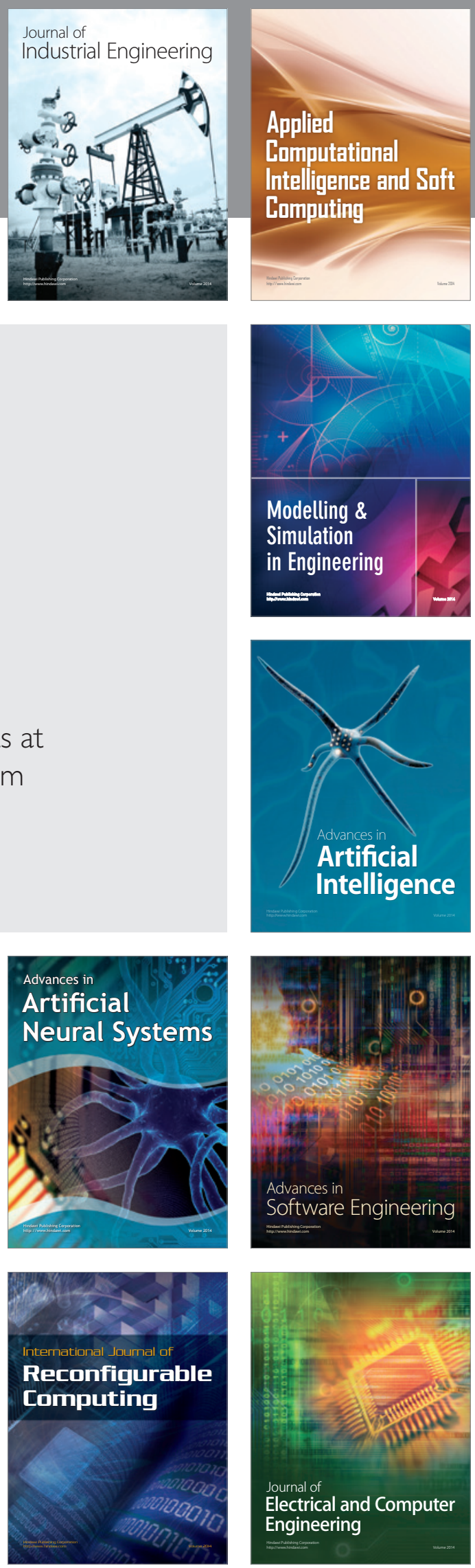